\title{
Indoor radon in Tunisian spas
}

\author{
S. LABIDI ${ }^{1}$, DARWISH AL-AZMI ${ }^{2}$, R. BEN SALAH ${ }^{3}$
}

(Manuscript received 25 November 2011, accepted 4 January 2012)

\begin{abstract}
Indoor radon concentrations were measured in four well-known spas of Tunisia using nuclear track detectors. The radon concentrations in these spas were found to be in the range of $19-870 \mathrm{~Bq} \cdot \mathrm{m}^{-3}$. The equilibrium factor $\mathrm{F}$ between radon and its progeny was found to vary in the range of $0.2-0.5$, depending upon the ventilation rates within the buildings of the spas. Using the exposure-dose conversion factor, the effective doses to patients and workers were estimated and the dose was found to vary in the range $3.7 \times 10^{-3}-12.5 \times 10^{-3} \mathrm{mSv}^{-1}$ and $0.45-1.5 \mathrm{mSv} . \mathrm{y}^{-1}$ for patients and workers, respectively. These values are well inside the limit recommended for the annual dose limit of $20 \mathrm{mSv}^{-1} \mathrm{y}^{-1}$ for an occupational worker. The radium content in the groundwater of all four spas was measured and the results showed no correlation between the ${ }^{226} \mathrm{Ra}$ concentration in water and radon concentration in indoor air of the investigated spas.
\end{abstract}

Keywords: radon / hydrotherapy centers / effective dose / equilibrium factor / Tunisia

\section{Introduction}

Radon $\left({ }^{222} \mathrm{Rn}\right)$ is a naturally occurring radioactive gas formed by the decay of ${ }^{226} \mathrm{Ra}$, which decays into a series of short-lived radioactive products. Radon and its decay products (progeny) are recognized as the most significant natural source of human radiation exposure (UNSCEAR, 2006) and the most important cause of lung cancer incidence except for smoking (US-EPA, 2003). Thus, numerous radon measurements have been carried out in dwellings as well as in various workplaces worldwide. These studies aimed to estimate the health hazards and also to investigate and suggest ways of reducing the radon levels inside the dwellings and workplaces.

The spas used for thermal therapy are known to have higher concentration levels of radon and its progeny, and patients and workers of such spas are expected to be exposed to higher concentration levels of radon and its progeny, leading to a significant additional radiation burden (Szerbin, 1996; Vogiannis et al., 2004; Manic et al., 2006; Nikolopoulos et al., 2010).

\footnotetext{
${ }^{1}$ Institut Supérieur des Technologies Médicales de Tunis (ISTM), 9 avenue du Docteur Z. Essafi, Tunis 1006, Tunisia. e-mail: labidisalam@yahoo.fr

${ }^{2}$ Department of Applied Sciences, College of Technological Studies, Public Authority for Applied Education and Training, P.O. Box 42325, 70654 Shuwaikh, Kuwait. email: ds.alazmi@paaet.edu.kw

${ }^{3}$ Faculté de Médecine de Sousse. 270, Sahloul II, 4054 Sousse, Tunisia.
} 
The EU identified this fact in the directive 96/29/EURATOM and proposed spa therapy as a professional activity of enhanced natural radiation exposure (CEC, 1996). Groundwaters are in close contact with soil and rocks containing radium. Once formed by its decay from radium, radon gas may diffuse through rock pores and geological discontinuities and dissolve in these waters. Radon is transported to the surface and it can easily diffuse into the atmosphere, and may produce elevated radon levels in places such as thermal spas. The presence of radium in springs can be an indicator of elevated indoor radon concentration in the dwellings of the surrounding area, and radium concentration measurements in springs could serve as one of the initial stages of a radon survey (Onishchenko et al., 2010).

The high radon concentrations in spas are a source of risk mainly for staff and, to a lesser extent, for the patients (Ródenas et al., 2008). The practice of using springs for medical purposes has increased considerably and new modernized buildings have appeared, linked to the utilization of several water springs that have been used up to the present time. Today, spas are becoming increasingly important as recreation sites or as health resorts and, at present, there are many such centers, most of them fully modernized, in operation.

\subsection{Thermal spas in Tunisia}

In Tunisia, thermal waters are frequently recommended by health specialists for refreshing and medical purposes. These waters have variable amounts of certain dissolved substances that, in some cases, are identified with beneficial health effects (Kovacs and Bender, 2002; Sukenik et al., 1999). These substances and the high temperature of the water act as coadjuvant agents in health conditions such as rheumatism, arthrosis, arthritis and respiratory tract disorders. Among these dissolved substances there are some series of radioactive elements of natural origin that may result in elevated levels of radiation exposure.

Waters of the hot springs of Tunisia have been analyzed for geological, hydrogeological, geochemical and geophysical parameters (Grünberger et al., 2004; Inoubli et al., 2006; Bouri et al., 2007). In addition, one preliminary study was done for the radium content and the results showed that the spa of Jebel Oust had the highest radium concentration in its water. Thus, a study was conducted in this spa (Jebel Oust) for the indoor radon within its building. The findings indicated that the mean indoor radon concentrations were very low, and the risk due to the inhalation of radon was found to be negligible, as was published in a previous work (Labidi et al., 2006). 


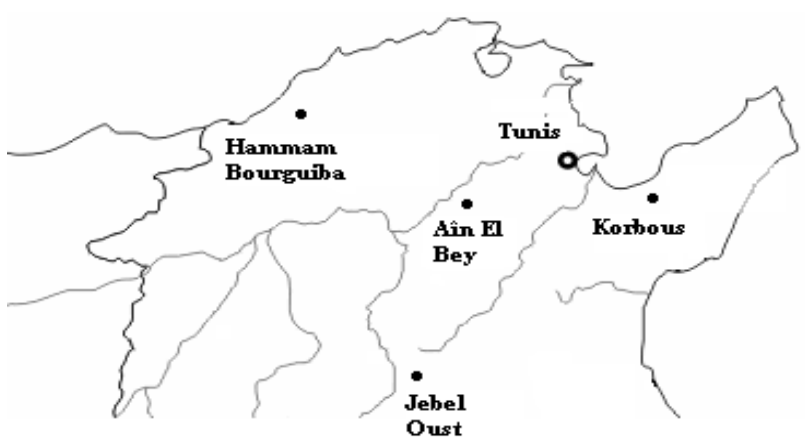

Figure 1 - Locations of the thermal spas of Northern Tunisia studied in the present work.

\section{Present survey}

The aim of the present work is further study the indoor radon concentration levels in the thermal spas of Tunisia, one private and three modern spas. The results are discussed to evaluate the effective doses from the inhalation of radon and its decay products and to provide an estimate of exposure due to such natural radiation.

Four thermal spas in Tunisia were considered, Hammam Bourguiba, Koubous, Jebel Oust and Aïn El Bey, that are located in northern Tunisia in the governorates of Jendouba, Nabeul, Zaghouan and Ben Arous, respectively. Figure 1 shows the locations of these spas on the map of Tunisia.

\subsection{Spas covered under the study}

The first three thermal spas (Hammam Bourguiba, Koubous and Jebel Oust) are large with modern facilities and they are considered as modern spas. A large number of patients are treated in these three spas, which are recommended for respiratory tract disorders and bronchopulmonary pathologies, rhino-pharynx, pharynx and amydales larynx, pneumology, tubo-tympanic cavities, dermatology, rheumatology, and gynaecology. These spas have treatment rooms that are supplied with spring water. Spring water is pumped from its source by means of a mechanical drainage system located a few meters outside the spa premises. In most cases, pumped water is stored in a water tank before treatment. However, in some cases the pumped water is used directly for treatment. The treatment rooms have windows for natural ventilation, and a small mechanical system which may be utilized for forced ventilation as well as centralized heating systems. 
TABLE I

Details of spring waters used in the spas of Tunisia.

\begin{tabular}{|c|c|c|c|c|c|}
\hline Governorate & Spas & Temp $\left({ }^{\circ} \mathrm{C}\right)$ & $\begin{array}{c}\text { Minerals } \\
\left(\mathrm{g} \mathrm{L}^{-1}\right)\end{array}$ & $\begin{array}{l}\text { Altitude } \\
\text { (m) }\end{array}$ & Hydrochemical type \\
\hline Jendouba & $\begin{array}{l}\text { Hammam } \\
\text { Bourguiba }\end{array}$ & 50 & 18.68 & 150 & $\begin{array}{c}\text { Sulphated sodic } \\
\text { bicarbonated }\end{array}$ \\
\hline Nabeul & Korbous & 60 & 1.0 & 51 & Sodic chloride \\
\hline Zaghouan & Jebel Ouest & 54 & 18.68 & 130 & Sodic chloride \\
\hline Ben Arous & Aïn El Bey & 43 & 15.81 & 8 & Sulphated sodic chloride \\
\hline
\end{tabular}

The fourth spa "Aïn El Bey" is small and known as a popular spa. It is considered the most ancient bathing resort of Tunisia, used since the Roman period. This old spa has neither air conditioning nor any air ventilation system.

The thermal waters used in the above spas contain a wide variety of substances in solution, depending on the characteristics of the soil types through which the water passes. The background information of the spring waters of these spas is listed in Table I.

\section{Materials and method}

\subsection{Radon measurements}

Solid-state nuclear track detectors (LR-115 type films: Kodalpha, supplied by Dosirad, Paris, France) were used in this study to provide accumulated radon measurements for a period of a few months. Two track detectors were used in each location; one was kept inside a closed cup, which was provided with pin holes on the top to allow the entry of radon only, and the other was left open to allow the measurements of radon and its progeny. The use of two radon dosimeters (closed and open) enabled the estimation of the equilibrium factor $F$ between radon and its progeny in air for a better assessment of the radon dose.

Different locations inside the spas were chosen for the radon measurements. The locations chosen were mainly the places where patients undergo treatments (shower and bath rooms as well as the swimming pool areas). The detectors were installed for exposure in the selected locations for a duration of about 5 months in the period during November 2009 to March 2010. Then, the nuclear track detectors were collected and sent to the Dosirad laboratory (France) for etching and reading. Different calibrations are used for each set of the open and closed detectors to estimate the radon concentration levels as well as to calculate the equilibrium factors between radon and its progeny (Labidi et al., 2010). 
INDOOR RADON IN TUNISIAN SPAS

\section{2. ${ }^{226}$ Ra measurements}

The concentration of ${ }^{226} \mathrm{Ra}$ in the spring waters was analyzed by gamma spectrometry. Twenty liters of each spring's water were collected in polyethylene bottles with screw caps and immediately acidified to $\mathrm{pH} \approx 2$ with concentrated $\mathrm{HNO}_{3}$. A known quantity of barium, in the chemical form of $\mathrm{BaCO}_{3}$, was then added to each water sample. After stirring, Ra isotopes were co-precipitated with $\mathrm{BaSO}_{4}$ formed by the addition of $\mathrm{H}_{2} \mathrm{SO}_{4}$ (in drops) to the medium without significant change of the $\mathrm{pH}$ of the sample. After decantation, the precipitate containing radium was separated from the sample by centrifuging. The insoluble $\mathrm{BaSO}_{4}$ was rinsed with deionized water, and dried at room temperature. The obtained powder was sealed inside a plastic ferrule with a size compatible with the dimensions of the well-type germanium detector used in the study. The detector used for the study was a $220-\mathrm{cm}^{3}$ low-background well-type germanium gammaray detector. The gamma-ray spectrum for each sample was acquired after 3 weeks, which is adequate to ensure radioactive equilibrium between Ra isotopes and their daughters (Reyss et al., 1995). All the results obtained are given with uncertainties of $1 \sigma$.

\section{Results and discussion}

The radon concentration in air was measured in all treatment areas of the four thermal spas and in the areas where the staff work. However, some difficulties appeared during this survey, such as the high temperature of the steam within some of the locations as well as high relative humidity. Other difficulties were related to the acceptance of the dosimeters to be distributed in the private spa and also the loss of some of the dosimeters in this survey, particularly in the private spa.

The results of the indoor radon measurements in Tunisian spas are summarized in Table II. The radon concentrations in the air inside the three modern spas were measured at different locations including points close to the spring (gallery) and inside the therapy rooms. The radon concentrations at different points in the spas were found to vary in the range $19-313 \mathrm{~Bq} \cdot \mathrm{m}^{-3}, 19-335 \mathrm{~Bq} \cdot \mathrm{m}^{-3}$ and $45-589 \mathrm{~Bq} \cdot \mathrm{m}^{-3}$, for Hammam Bourguiba, Korbous and Jebel Oust spas respectively, considering different care rooms covered under this study. Inhomogeneous distribution of concentration was observed over all the treatment rooms of the spas. It is evident that the concentration of radon in the indoor air of the spas varied from one treatment room to another, due to the influence of several factors such as the size of the room, the ventilation rate and water flow rates. The highest concentrations were found in the bathrooms, with a mean value of $135 \mathrm{~Bq} \cdot \mathrm{m}^{-3}$. This was attributed to the continuous degassing of radon due to the continuous filling up of baths. The 
TABLE II

Indoor radon concentrations in different locations inside the spas.

\begin{tabular}{|c|c|c|c|}
\hline Spa & Floor & Care room & $\mathrm{C}_{\mathrm{Rn}}\left(\mathrm{Bq} \cdot \mathrm{m}^{-3}\right)$ \\
\hline \multirow{10}{*}{$\begin{array}{l}\text { Hammam } \\
\text { Bourguiba }\end{array}$} & Ground floor & Shower fusion & $19 \pm 5$ \\
\hline & & Hydromassage & $24 \pm 4$ \\
\hline & & Mud application & $26 \pm 6$ \\
\hline & & Jet shower & $26 \pm 6$ \\
\hline & & Chromatherapy & $25 \pm 5$ \\
\hline & & Shower submarine & $24 \pm 5$ \\
\hline & & Inhalation room & $23 \pm 5$ \\
\hline & & Swimming pool & $33 \pm 12$ \\
\hline & & Gallery & $313 \pm 22$ \\
\hline & Underground & $\begin{array}{l}\text { Turkish Bath women } \\
\text { Turkish Bath men }\end{array}$ & $\begin{array}{c}134 \pm 6 \\
48 \pm 7\end{array}$ \\
\hline \multirow{5}{*}{ Koubous } & Ground floor & Jacuzzi & $25 \pm 6$ \\
\hline & & Shower jet & $31 \pm 7$ \\
\hline & & Shower submarine & $335 \pm 27$ \\
\hline & First floor & Shower lumbar & $21 \pm 5$ \\
\hline & & Jacuzzi & $19 \pm 6$ \\
\hline \multirow{11}{*}{ Jebel Oust } & Underground & Steam therapy room & $352 \pm 25$ \\
\hline & & Inhalation room & $313 \pm 21$ \\
\hline & & Mud Application & $333 \pm 27$ \\
\hline & & Shower-bath & $58 \pm 9$ \\
\hline & & Bath room & $75 \pm 12$ \\
\hline & & Underwater Massage & $53 \pm 9$ \\
\hline & Ground floor & Swimming pool & $45 \pm 7$ \\
\hline & & Gallery & $589 \pm 31$ \\
\hline & First floor & Bathroom & $111 \pm 14$ \\
\hline & & Pediluvium \& Maniluvium & $91 \pm 11$ \\
\hline & & Shower-bath & $143 \pm 17$ \\
\hline \multirow{3}{*}{$\begin{array}{c}\text { Aïn } \\
\text { El Bey }\end{array}$} & Ground floor & Turkish Bath women & $870 \pm 44$ \\
\hline & & Bathroom & $215 \pm 19$ \\
\hline & & Turkish Bath men & $529 \pm 26$ \\
\hline
\end{tabular}

water flow during the filling of the bath causes degassing of radon. The agitation of the water caused by the bathers during swimming is the major mechanism by which radon is released into the air of the bathroom. These spas showed radon concentrations in air that were similar to those measured indoors in dwellings in the same area (El May et al., 2004).

It is interesting to note that the radon concentration in galleries is higher when compared with rooms of the same spa by a factor of 5, ranging from 313 to $589 \mathrm{~Bq} \cdot \mathrm{m}^{-3}$. This may be due to the proximity of the thermal water source. In the galleries, ventilation is poor and there is a high level of steam, and this may be the reason for the higher radon concentration in the galleries. Whereas, the other rooms of the spa are situated away from the thermal water source and during the transport of water from the spring to the different rooms degassing of radon occurs, 
and this may be the reason for the reduced radon concentration in other rooms. A decrease of up to $80 \%$ in the concentration of radon when the water is transferred from the spring to the therapy rooms was reported (Fontan et al., 1980; Améon et al., 2000). As presented in Table II, the overall radon concentration values tend to be relatively higher at lower levels that are closer to the soil radon source. The radon concentrations measured in basement and ground floor workplaces were somewhat higher than those measured on the first floor.

The modern spas covered in this study have efficient ventilation and centralized heating systems and this has helped in reducing the radon concentration levels in therapy rooms. The use of heating and air-conditioning systems has proved to be a significant factor in reducing the radon concentration inside the rooms (Marley, 1999). Also, the use of central heating systems in workplaces was found to decrease the radon and progeny concentration by more than $40 \%$ during the heating period of a normal working day (Marley et al., 2000). This decrease was attributed to the variation of indoor temperature, that induced a change in the advective gas flow rate. Investigating radon in commercial settings, Panatto et al. (2006) concluded that radon concentrations were lower by a factor of three in shops with central heating installations when compared with those equipped with individual heating systems.

On the other hand, the radon concentrations in different locations of the popular spa of Aï El Bey, which is an old spa (which has existed since the Roman period), varied in the range $215-870 \mathrm{~Bq} \cdot \mathrm{m}^{-3}$. These values are significantly higher when compared with those observed in the modern spas. In addition, the thermal spa of Aïn El Bey was characterized by high relative humidity and poor ventilation. This spa has no windows or a ventilation system to refresh air inside the premises. In this spa, people use the thermal water that comes straight from the source; there is no storage of water in reservoirs as in the case of the other modern spas. In fact, the gassing of radon from the water before use greatly reduces the levels of radon in the air treatment rooms. Nevertheless, in most cases, the observed values in Ain El Bey are not very high and they are comparable with the values reported for other spas in many regions worldwide (Radolic et al., 2005; Song et al., 2005; Nikolopoulos and Vogiannis, 2007; Vogiannis and Nikolopoulos, 2008).

\section{1. ${ }^{226}$ Ra content and radon concentration levels}

High radon concentration levels are usually associated with the presence of high concentrations of radium underground. In most cases, the major component of radon entrance into building structures is the subjacent soil. Significant differences in the concentrations of radon in indoor air have been found depending on the geological characteristics of the reference area. The highest levels are usually 
TABLE III

Concentration of ${ }^{226} \mathrm{Ra}$ in spring water, ${ }^{222} \mathrm{Rn}$ in air, equilibrium factor, potential Alpha Energy Concentration (PAEC) and the effective dose from inhalation of radon.

\begin{tabular}{|c|c|c|c|c|c|c|c|}
\hline \multirow[t]{2}{*}{ Spas } & \multirow[t]{2}{*}{$\begin{array}{c}{ }^{226} \mathrm{Ra} \\
\left(\mathrm{mBq} \cdot \mathrm{L}^{-1}\right)\end{array}$} & \multicolumn{2}{|c|}{${ }^{222} \mathrm{Rn}\left(\mathrm{Bq} \cdot \mathrm{m}^{-3}\right)$} & \multirow[t]{2}{*}{$\begin{array}{c}\text { Mean } \\
\text { F-factor }\end{array}$} & \multirow{2}{*}{$\begin{array}{c}\text { Mean value } \\
\text { PAEC } \\
\left(\mathrm{nJ} . \mathrm{m}^{-3}\right)\end{array}$} & \multicolumn{2}{|c|}{$\begin{array}{l}\text { Mean value ED } \\
\left(\mathrm{mSv} \cdot \mathrm{y}^{-1}\right)\end{array}$} \\
\hline & & Mean & Range & & & Workers & Patients \\
\hline Hammam Bourguiba & $200 \pm 15$ & $63 \pm 9$ & $19-313$ & 0.50 & 175 & 0.45 & $3.7 \times 10^{-3}$ \\
\hline Korbous & $750 \pm 23$ & $87 \pm 12$ & $19-335$ & 0.43 & 208 & 0.53 & $4.4 \times 10^{-3}$ \\
\hline Jebel Ouest & $4089 \pm 84$ & $175 \pm 23$ & $45-589$ & 0.35 & 340 & 0.87 & $7.2 \times 10^{-3}$ \\
\hline Aïn El Bey & $532 \pm 12$ & $538 \pm 28$ & $215-870$ & 0.20 & 598 & 1.5 & $12.5 \times 10^{-3}$ \\
\hline
\end{tabular}

found in granites (Ródenas et al., 2008) but concentrations vary considerably between each lithology. The geological structure of northern Tunisia (the area where the mentioned spas are situated) consists mainly of sedimentary formations where calcareous rocks are predominant.

The highest value for the radium concentration was found to be $4089 \mathrm{mBq} . \mathrm{L}^{-1}$ in the spring water of Jebel Oust (Tab. III). However, the indoor radon concentration levels were found to be relatively low in this spa. Based on the present findings, no correlation was found between the presence of ${ }^{226} \mathrm{Ra}$ in waters and high radon concentrations in the indoor air of spas investigated in this survey. The results obtained in our study are contrary to what was expected with regards to the values of radon found in indoor air. This is more pronounced for Aïn El Bey spa resort, where there is little correlation between the radium content and the radon values. Therefore, the presence of radium at high concentration in waters may not be considered as an indicator for high concentration of radon in indoor air in the spa. The concentrations of radon in indoor air do not depend on levels of dissolved ${ }^{226} \mathrm{Ra}$ in waters that supply the thermal spa; instead, such radon concentration levels depend strongly on the water flow pattern, the ventilation conditions and the use of central heating systems.

\subsection{The estimation of the equilibrium factor and the assessment of dose}

To estimate the equilibrium factor $\mathrm{F}$ between radon and its progeny, two detectors (one with pin holes and the other open) were used simultaneously, as mentioned earlier. The results of the equilibrium factor are presented in column 5 of Table III. The equilibrium factors varied from 0.2 to 0.5 , which is because of the different ventilation rates within the spas. Figure 2 is a correlation plot of radon concentration in air and the equilibrium factor $\mathrm{F}$. It is interesting to note that the equilibrium factor $\mathrm{F}$ is in inverse relation to the radon concentration in air, with a high correlation coefficient, $\mathrm{R}=0.92$. This indicates that high radon concentrations do not 


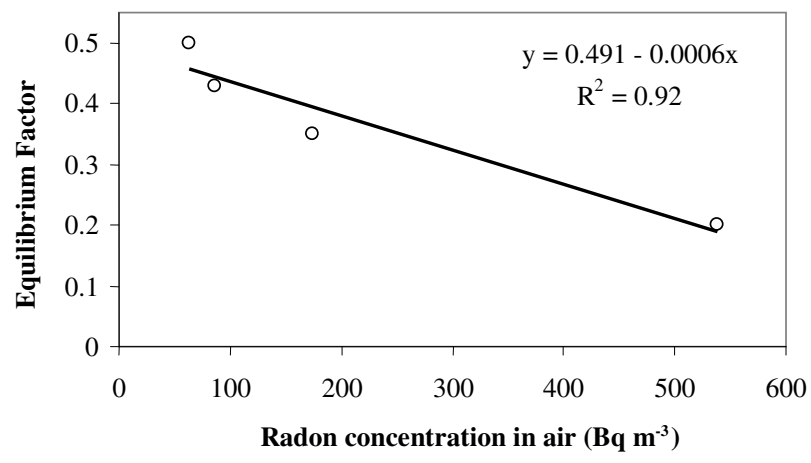

Figure 2 - Correlation between radon concentration in air and equilibrium factor.

necessarily imply high levels of radon daughters. The reason for such an observation in the spas may be because of the increased washout of aerosols under high humidity conditions. The water droplets settling causes the washout of particles from the indoor air, reducing the concentration of radon progeny in the air, and hence the lower $\mathrm{F}$ value.

The health risk associated with the inhalation of ${ }^{222} \mathrm{Rn}$ and its progeny by the patients and the workers inside the spa is related to the potential alpha energy concentration (PAEC) measured in $\mathrm{J}^{-3} \mathrm{~m}^{-3}$ (ICRP, 1993) and the same was also calculated in the present work: the results are presented in column 6 of Table III. The short-lived ${ }^{222} \mathrm{Rn}$ progeny emit alpha particles and they contribute significantly to the inhalation dose. However, the biological effects of beta particles are negligible when compared with those of alpha particles and the risk is related only to the potential alpha energy concentration (PAEC). The potential alpha energy concentration is defined by the following equation:

$$
\operatorname{PAEC}\left(\mathrm{J}_{\mathrm{m}} \mathrm{m}^{-3}\right)=5.56 \times 10^{-9} \times \mathrm{C}_{\mathrm{Rn}} \times \mathrm{F}
$$

where $C_{R n}$ is the activity concentration of ${ }^{222} \mathrm{Rn}$ in Bq.m ${ }^{-3}, 5.56 \times 10^{-9}$ is the potential alpha energy of radon progeny per unit activity of radon gas at equilibrium, and $\mathrm{F}$ is the estimated equilibrium factor for ${ }^{222} \mathrm{Rn}$.

The exposure of workers and patients in the thermal spa due to the inhaled ${ }^{222} \mathrm{Rn}$ and its decay products in each site is related to the PAEC and to time T (time of exposure) spent in this environment. The annual occupation time was calculated to be $1840 \mathrm{~h}$ for any worker inside the spa. This occupation time is calculated based on a total of 230 working days per year for $8 \mathrm{~h}$ per day. For the patient, this factor 
is calculated considering 30 treatment visits per year and the time duration of each treatment is considered to be $30 \mathrm{~min}$. Hence, the exposure (EX) due to the inhaled ${ }^{222} \mathrm{Rn}$ and its decay products is given by:

$$
\mathrm{EX}\left(\mathrm{J} \cdot \mathrm{h} \cdot \mathrm{m}^{-3}\right)=(\mathrm{PAEC}) \times \mathrm{T}(\mathrm{h})
$$

For the determination of the effective dose for workers and patients, a relation between the potential alpha energy concentration of the radon progeny exposure and dose, the dose conversion factor $(\mathrm{DCF}=$ dose/[PAEC $\times \mathrm{T}])$ is needed, which was estimated as $1.4 \mathrm{mSv}^{-1}$ per unit of exposure to potential alpha energy $\left(\mathrm{mJ} . \mathrm{h} . \mathrm{m}^{-3}\right)$, recommended in ICRP Publication 65 (ICRP, 1993). For the estimation of the dose conversion factor, several dosimetric models have been proposed. Since the dose and the health detriment depend mainly on the radon progeny rather than the radon gas, the measurement of the equilibrium factor $\mathrm{F}$ is important to apply the ICRP (1993) dose conversion convention to the data of radon gas activity measurement. In the epidemiological approach retained by the ICRP, the fraction of radon decay products attached or unattached to ambient aerosol is not taken into account. However, to apply a dosimetric model (i.e., ICRP, 1993), the determination of such an unattached fraction would be important. In the present study, the measurement of the unattached fraction was not performed. For accurate dose assessment, it is advisable to make aerosol-size distribution measurements.

The mean annual dose received by the workers of the thermal spas studied in the present work is found to vary in the range $0.45-1.5 \mathrm{mSv} \cdot \mathrm{y}^{-1}$, which is very much within the permitted limit $\left(20 \mathrm{mSv}^{-1} \mathrm{y}^{-1}\right)$ (ICRP, 1993). Whereas, the corresponding doses for patients varied from $2.9 \times 10^{-3}$ to $9.8 \times 10^{-3} \mathrm{mSv} \cdot \mathrm{y}^{-1}$. Figure 3 provides a comparison of the doses received by the workers and the patients.

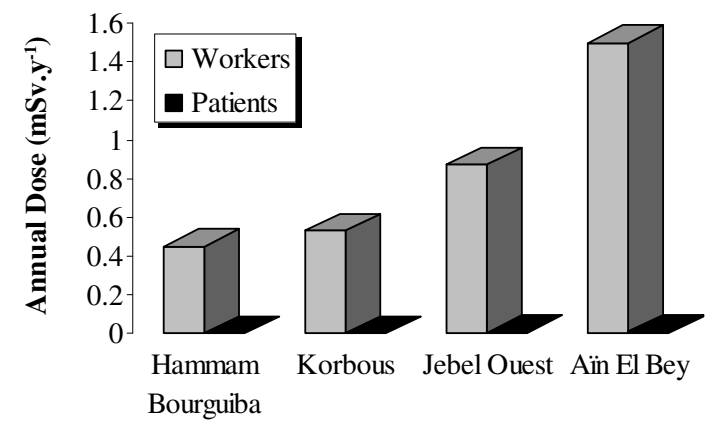

Thermal Spas

Figure 3 -Annual effective doses for workers and patients due to the inhalation of radon in thermal spas. 
Even though the concentration of ${ }^{222} \mathrm{Rn}$ is high in the Aï El Bey thermal spa $\left(870 \mathrm{~Bq} \cdot \mathrm{m}^{-3}\right)$, and the indoor environment of this spa is hot and humid, with a high level of steam and without any ventilation, the employees would not be considered to be occupationally exposed and therefore, radiation protection control is not necessary, particularly when it is compared with the values reported for spas in other countries where effective doses may reach up to several tens of $\mathrm{mSv} \cdot \mathrm{y}^{-1}$ (Besançon, 1990). The few studies in the world carried out on this subject confirm those high values of effective doses received by workers. It is necessary, therefore, to consider radon as an important source of occupational exposure in thermal spas (Lettner et al., 1996; Soto and Gomez, 1999; Améon, 2003).

\section{Conclusion}

Measurements of ${ }^{222} \mathrm{Rn}$ concentrations in indoor air of spas in Tunisia were carried out using LR-115 nuclear track detectors. The ${ }^{222} \mathrm{Rn}$ concentration in indoor air of spas in Tunisia varied in the range of $19-870 \mathrm{~Bq} \cdot \mathrm{m}^{-3}$. The measurement of ${ }^{226} \mathrm{Ra}$ concentration in different spring waters revealed that high radium concentration in water does not necessarily lead to elevated concentrations of radon in indoor air of spa buildings. Equilibrium factors between radon and its progeny in the treatment rooms were found to vary between 0.2 and 0.5 , which is due to different ventilation rates within the spas. The radiation dose in different treatment rooms varied depending on factors such as therapy room size, ventilation rate, central heating systems and time spent in the bathroom.

Estimation of the effective dose received by the workers in the Aïn El Bey spa gave the value of $1.5 \mathrm{mSv} \cdot \mathrm{y}^{-1}$, which is very much within the permitted limit recommended by the ICPR (1993).

\section{REFERENCES}

Améon R. (2003) Le radon dans les stations thermales : une source d'exposition aux rayonnements ionisants, Radioprotection 38, 201-215.

Améon R., Beneïto A., Thoreux A. (2000) Étude de l'activité volumique en radon dans une station thermal française, Cas d'Évaux-les-bains, Rapport DPRE/SERGD/00-51, IPSN.

Besançon F. (1990) Radon thermal inhale, Presse Thermale et Climatique 127, 1-26.

Bouri S., Gasmi M., Jaouadi M., Souissi A., Lahlou M., Ben Dhia H. (2007) Étude intégrée des données de surface et de subsurface pour la prospection des bassins hydrogéothermiques : cas du bassin de Maknassy (Tunisie centrale), Hydrological Sciences Journal 52 (6), 1298-1315.

CEC (Council of the European Union) (1996) Council Directive 96/29/Euratom of 13 May 1996, Off. J. Eur, Communities, L-159 of 29.6.

El May M.V., Chahed N., Mtimet S. (2004) Radon concentrations in some dwellings of Tunisia, Health Phys. 86, 150-154. 
Fontan M., Caridroit M., Erb F., Tauzide-castel C. (1980) Quelques études sur l'action des eaux, boues et gaz thermaux radioactifs de Saint-Amand-les-eaux, J. Fr. Hydrol. 11, 55-62.

Grünberger O., Montoroi J.P., Slah N. (2004) Quantification of water exchange between a hill reservoir and groundwater using hydrological and isotopic modeling (El Gouazine, Tunisia), $C$. $R$. Geoscience 336, 1453-1462.

ICRP Publication 65 (1993) International Commission on Radiological Protection, Protection against radon-222 at home and at work, Ann. ICRP 23.

Inoubli N., Gouasmia M., Gasmi M., Mhamdi A., Ben Dhia H. (2006) Integration of geological, hydrochemical and geophysical methods for prospecting thermal water resources: The case of the Hmeïma region (Central-Western Tunisia), J. Afr. Earth Sci. 46, 180-186.

Kovacs I, Bender T. (2002) The therapeutic effects of Cserkeszolo thermal water in osteoarthritis of the knee: a double blind, controlled, follow-up study, Rheumatol. Intern. 21, 218:221.

Labidi S., Al Azmi D., Mahjoubi H., Ben Salah R. (2010) Radon in elementary schools in Tunisia, Radioprotection 45 (2), 209-217.

Labidi S., Essafi F., Mahjoubi H. (2006) Estimation of the radiological risk related to the presence of radon 222 in a hydrotherapy centre in Tunisia, J. Radiol. Prot. 26, 1-8.

Lettner H., Hubmer A.K., Rolle R., Steinhausler F. (1996) Occupational exposure to radon in treatment facilities of the radon-spa Badgastein, Austria, Environm. Intern. 22, Suppl. 1, S399-S407.

Manic G., Petrovic S., Vesna M., Popovic D., Todorovic D. (2006) Radon concentrations in a spa in Serbia, Environm. Inter. 32, 533-537.

Marley F. (1999) Investigation of atmospheric, mechanical and other pressure effects influencing the levels of radon and radon progeny in buildings, Health Phys. 77 (5), 556-570.

Marley F., Denman A.R., Phillips P.S. (2000) Examination of the influence of water-heated central heating systems on the levels of radon and progeny in the workplace, Radiat. Meas. 32, 15-25.

Nikolopoulos D., Vogiannis E. (2007) Modelling radon progeny concentration variations in thermal spas, Sci. Tot. Environ. 373, 82-93.

Nikolopoulos D., Vogiannis E., Petraki E., Zisos A., Louizi A. (2010) Investigation of the exposure to radon and progeny in the thermal spas of Loutraki (Attica, Greece): Results from measurements and modeling, Sci. Tot. Environm. 408, 495-504.

Onishchenko A., Zhukovsky M., Veselinovic N., Zunic Z.S. (2010) Radium-226 concentration in spring water sampled in high radon regions, Appl. Radiat. Isot. 68, 825-827.

Panatto D., Ferrari P., Lai P., Gallelli G. (2006) Relevance of air conditioning for radon concentration in shops of the Savona Province, Italy, Sci. Tot. Environ. 355, 25-30.

Radolic V., Vukovic B., Smit G., Stanic D., Planinic J. (2005) Radon in the spas of Croatia, J. Environ. Radioact. 83, 191-8.

Reyss J.-L., Schmidt S., Legeleux F., Bonte P. (1995) Large, low background well-type detectors for measurements of environmental radioactivity, Nucl. Instrum. Meth. Phys. Res. A 357, 391-397.

Ródenas C., Gomez J., Soto J., Maraver F. (2008) Natural radioactivity of spring water used as spas in Spain, J. Radioanal. Nucl. Chem. 277 (3), 625-630.

Song G., Zhang B., Wang X., Gong J., Chan D., Bernett J., et al. (2005) Indoor radon levels in selected hot spring hotels in Guangdong, China, Sci Total Environ. 339, 63-70.

Soto J., Gomez J. (1999) Occupational doses from radon in Spanish Spas, Health Phys. 76 (4), 398401.

Sukenik S., Flusser D., Abu-Shakra M. (1999) The role of spa therapy in various rheumatic diseases, Rheum. Dis. Clin. North Am. 25 (4), 883-97.

Szerbin P. (1996) Natural radioactivity of certain spas and caves in Hungary, Environ. Int. 22, S389S398. 
INDOOR RADON IN TUNISIAN SPAS

UNSCEAR (2006) United Nations Scientific Committee on the Effects of Atomic Radiation, Report to the General Assembly, Annex A: Epidemiological studies of radiation and cancer.

US-EPA (2003) United States Environmental Protection Agency. Air and radiation (6608 J), EPA assessment of risk from radon in houses, EPA 402-R-03-003, Washington, DC, U.S. EPA.

Vogiannis E., Nikolopoulos D. (2008) Modelling of radon concentration peaks in thermal spas: application to Polichnitos and Eftalou spas (Lesvos Island-Greece), Sci. Total Environ. 405, 36-44.

Vogiannis E., Nikolopoulos D., Louizi A., Halvadakis C.P. (2004) Radon exposure in the thermal spas of Lesvos Island-Greece, Radiat. Prot. Dosim. 111 (1), 121-127. 